\title{
Supercapacitor based PV measurement technique - quality assessment with poly-Si PV modules at IIEST, Kolkata
}

\author{
Sudipta Basu Pal ${ }^{1, *}$, Rahul Kumar ${ }^{2}$, Konika Das Bhattacharya ${ }^{1}$, Dipankar Mukherjee ${ }^{2}$, and Debkalyan Paul ${ }^{2}$ \\ ${ }^{1}$ Electrical Engineering, Indian Institute of Engineering Science and Technology, Shibpur, Howrah, India \\ ${ }^{2}$ Electronics and Telecommunication Engineering, Indian Institute of Engineering Science and Technology, \\ Shibpur, Howrah, India
}

Received: 2 May 2019 / Accepted: 4 July 2019

\begin{abstract}
Supercapacitors have been used for the first time as load to PV cell/modules for characterizing their behavior. In this paper, a novel and essentially simple design of a $V-I$ plotter is attempted with a bank of super capacitors (SC) as the load to the PV modules of varying capacities. The distinct advantages of the SC's over the erstwhile capacitors have been comparatively experimented. Finally, an elaborate regression analysis (RA) of principal electrical parameters have yielded consistently high values exceeding 0.993 experimental evaluation of quality parameters like fill-factor $(\mathrm{FF})$ and performance ratio $(\mathrm{PR})$ have yielded a range of $70-79 \%$ while PR values frequently ranges from $90 \%$ to $99 \%$. Suitability of poly-Si PV modules at the level of PV panel configurations have been ascertained through experimental estimate of series and parallel relative power loss (RPL) values. Typical values below $2 \%$ obtained for widely varying climatic level is also a quality indicator for the new metrology in question. Such a prototype $I-V$ plotter is expected to be duly considered for commercial testing applications in PV industries.
\end{abstract}

Keywords: SPS / RES / PV power plants / supercapacitors / PV generators / performance ratio

\section{Introduction}

The rapid penetration of the solar photovoltaic systems (SPS) into the electrical networks at different voltage levels is now an accepted global phenomenon. Penetration of renewable energy sources (RES) into the average European grid is expected to cross $30 \%$ by the end of 2022 , $12 \%$ of such shares being specifically contributed from photovoltaics [1]. India has already embarked on a policy [2] of delivering at least $20 \%$ of grid-power through renewable energy sources (RES) by 2020. Accordingly, massive efforts are currently being undertaken in India for large-scale installations of PV power plants of megawatts capacity. This calls for an appropriate and smart metrological procedure for selecting the PV modules, acting as the building blocks to the high capacity $\mathrm{PV}$ arrays [1].

The aforesaid situation is responsible for expanding the role of an online, accurate and inexpensive $V-I$ plotter outside the academic laboratories also. Thus, the next section is essentially devoted to a review of the existing metrological approaches practiced in $\mathrm{PV}$

\footnotetext{
* Corresponding author: sudipta_basu68@yahoo.com
}

engineering for establishing the specific merits of the supercapacitor (SC) based method introduced by the authors. Here, supercapacitors have been used in the area of PV metrology for the first time as the load to the PV generators [3-5].

\section{Review of existing PV metrology}

The conventional analog method of determination of the $V-I$ characteristic of a solar module involves a variable resistance used as the load. A typical $V-I$ characteristics of any PV module is shown in Figure 1, where there are two extremities - the short circuit current point $\left(I_{\mathrm{sc}}, 0\right)$ and open circuit voltage point $\left(0, V_{\mathrm{oc}}\right)$. The standard electrical parameters of interest in any $V-I$ plot are the following: short circuit current $\left(I_{\mathrm{sc}}\right)$, open circuit voltage $\left(V_{\mathrm{oc}}\right)$, peak power current point $\left(I_{m}\right)$, peak power voltage point $\left(V_{m}\right)$, maximum power point $\left(P_{m}\right)$.

By varying the resistive load, the above co-ordinates can be approached but not reached. Further, this manual process consumes sufficient time leading to undesired heating of all the $p-n$ junctions of a PV module.

To minimize the human intervention and to characterize the PV module faster and accurately researchers started to use electronic loads instead of resistive loads. 


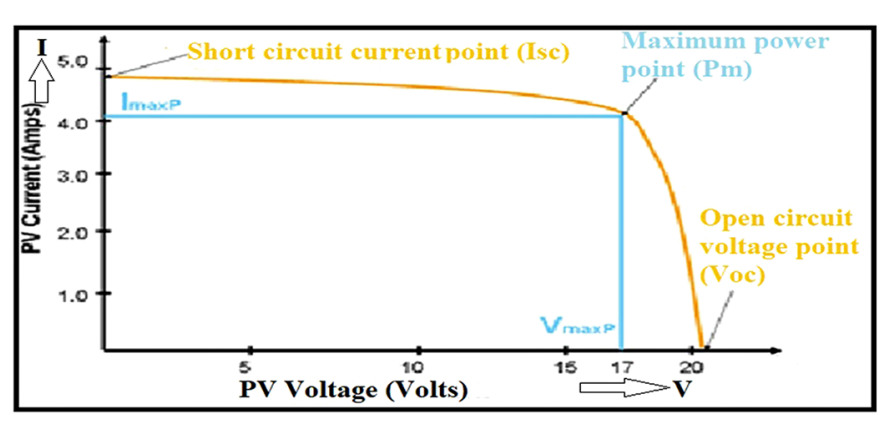

Fig. 1. Photovoltaic module voltage-current characteristics.

Linear MOSFET can be used as an electronic load to test the PV panel. Advantage of the electronic load is the fast variation (scanning) of the equivalent load resistance. Various commercial grade systems for testing PV panels under field conditions are available but they are computer controlled and are very expensive. A MOSFET based electronic load circuit was introduced by Kuai et al. [6]. Recently Sahbel et al. designed a simple electronic circuit for testing the photovoltaic (PV) modules by tracing their $I-V$ characteristics [7]. However, such methods are constrained by a requirement of an expensive test setup primarily suited to the laboratory measurement conditions only. In the next phase of development, researchers developed capacitor charging with the aid of open circuit voltage. Such an effort by Mahmoud [8] has used capacitors as the load to PV Generators. But, such reports contain a detailed transient analysis, which leads to the estimate of $I-V$ plotting time based on open circuit voltage $\left(V_{\mathrm{oc}}\right)$ and short circuit current $\left(I_{\mathrm{sc}}\right)$ only. Also, such reports do not contain real traces of $I-V$ characteristics of PV generators. Further, this method calls for a high precision matching DAS, rendering the plotter higher in capital cost, although other researchers like Erkaya et al. and Spertino et al. $[9,10]$ have in the recent past used capacitive load. Very recently Zhikong et al. [11] proposed new capacitor-based design and implementation of an $I-V$ characteristics tester. The setup is quite efficient to characterize PV arrays quickly. But this type of tracer is not able to characterize a single PV cell/module/panel. But neither of these curve tracers provides an assessment of the $V-I$ plotting time and effective means to control the same.

On the above backdrop, authors of this paper have introduced a new technique where Supercapacitors have replaced the capacitors with the plotting time modeled out as a function of four basic electrical parameters $\left(I_{\mathrm{sc}}, V_{\mathrm{oc}}, I_{m}\right.$, $V_{m}$ ) along with the effective series resistance (ESR) value of the SC bank. This is reported in details in an earlier publication [5].

On the above backdrop, authors of this paper have introduced a new technique where supercapacitors have replaced the capacitors with the plotting time modeled out as a function of four basic electrical parameters

- short circuit current $\left(I_{\mathrm{sc}}\right)$,

- open circuit voltage $\left(V_{\mathrm{oc}}\right)$,

- maximum current at maximum power point $\left(I_{m}\right)$ and maximum voltage at maximum power point $\left(V_{m}\right)$ along with the effective series resistance (ESR) value of the SC bank. This is reported in details in an earlier publication $[5]$.

\section{Advantages of super capacitors (SC) over capacitors}

In this work, supercapacitors have been used as a measuring element rather than a storage device. In this case, note worthy advantages of SC's are:

- Desirable control of the plotting time when the voltage of $\mathrm{SC}$ approaches $V_{\mathrm{OC}}$.

- The thermal management of the Supercapacitor bank is possible without the use of any kind of heatsink, as the heat dissipation is not expected to cross a level of few watts, prevailing for only $10-15 \mathrm{~s}$. This is clearly evidenced from Table 1.

- A high Coulombic efficiency exceeding 99\%, leading to fast sweep between $V=0$ to $V=V_{\text {oc }}$.

- A wide range of capacitances available with low ESR values (within few milliohms) [12].

- A voltage range compatible with the open circuit voltages of standard PV modules and panels.

To establish the superiority of supercapacitor-based loading method a comparative table for SC based and capacitor-based methods with respect to accuracy in estimation of curve tracing time is to be shown in Table 1.

Moreover, an experimental estimation of heat dissipation for $100 \mathrm{Wp} \mathrm{PV}$ modules using supercapacitors is shown in Table 2. The heat dissipation values in the last column have been estimated by considering individual ESR value of the supercapacitors to be $0.02 \Omega$ and the total ESR value of the Supercapacitor bank is $0.12 \Omega$ (optimum combination of six SC's in series). Same experiments were also carried out using capacitances of rating $10,000 \mu \mathrm{F}$, $25 \mathrm{~V}$ with 1 ohm ESR value and the charging currents utilized to estimate the different heat dissipation amounts as shown in Table 3 .

It is clearly seen from the above two tables that capacitor-based characterization calls for a separate heat sink to dissipate the excessive heat generated. Further disadvantage of using the capacitor as the load to the PV generator requires a higher volume, which also makes some capacitor-based plotters inconvenient for transportation.

\section{Characterization setup}

Figure 2 represents typically a block diagram of the testing scheme used by the authors.

The solar PV modules or panels (combination of PV modules) have been fitted into the steel structure and placed at the roof-top. Voltage and current inputs are via VC (voltage channel) and CC (current channel) respectively. For accurate insolation sensing a $3 \mathrm{Wp}$ c-Si solar PV panel has been placed and considered as the reference module. The module back surface temperature is measured using the resistance temperature detector (RTD) cables 
Table 1. Estimate of curve tracing time (for $10 \mathrm{Wp}, 74 \mathrm{Wp}$ and $100 \mathrm{Wp}$ poly-Si PV module).

\begin{tabular}{|c|c|c|c|c|c|c|}
\hline Module wattage & $\begin{array}{l}\text { Degree } \\
\text { of curve } \\
\text { tracing } \\
\mathrm{K} \%\end{array}$ & $\begin{array}{l}\text { Actual/ } \\
\text { experimental } \\
\text { curve tracing } \\
\text { time }\left(T_{\mathrm{ex}}\right)\end{array}$ & $\begin{array}{l}\text { Estimated curve } \\
\text { tracing time } \\
\text { as per capacitor } \\
\text { based method }\end{array}$ & $\begin{array}{l}\text { \% Error in capacitor } \\
\text { based method } \\
\text { (with respect } \\
\text { to experimental } \\
\text { curve tracing time) }\end{array}$ & $\begin{array}{l}\text { Estimated } \\
\text { curve tracing } \\
\text { time as per } \\
\text { supercapaitor } \\
\text { based method }\end{array}$ & $\begin{array}{l}\% \text { Error in SC based } \\
\text { method (with respect } \\
\text { to experimental } \\
\text { curve tracing time) }\end{array}$ \\
\hline \multirow{6}{*}{10 Wp Poly-Si } & 95.11447 & 3.8 & 14 & $268 \%$ & 3.914 & $3.00 \%$ \\
\hline & 96.73156 & 4.2 & 14.8 & $252 \%$ & 4.284 & $2.00 \%$ \\
\hline & 97.78194 & 4.6 & 15 & $226 \%$ & 4.784 & $4.00 \%$ \\
\hline & 98.74078 & 5.2 & 15.6 & $200 \%$ & 5.408 & $4.00 \%$ \\
\hline & 99.74064 & 7.5 & 16.6 & $121 \%$ & 7.601 & $1.35 \%$ \\
\hline & 99.99974 & 9 & 17 & $89 \%$ & 9.17 & $1.89 \%$ \\
\hline \multirow{6}{*}{74 Wp Poly-Si } & 95.11447 & 3.8 & 0.5 & $-87 \%$ & 3.914 & $3.00 \%$ \\
\hline & 96.73156 & 4.5 & 1.2 & $-73 \%$ & 4.8 & $6.67 \%$ \\
\hline & 97.78194 & 5 & 1.5 & $-70 \%$ & 5.2 & $4.00 \%$ \\
\hline & 98.84078 & 5.8 & 1.8 & $-69 \%$ & 6 & $3.45 \%$ \\
\hline & 99.6864 & 6.5 & 2 & $-69 \%$ & 6.7 & $3.08 \%$ \\
\hline & 99.99884 & 7.2 & 2.4 & $-67 \%$ & 7.3 & $1.39 \%$ \\
\hline \multirow{6}{*}{100 Wp Poly-Si } & 95.11447 & 2.8 & 1.6 & $-43 \%$ & 2.95 & $5.36 \%$ \\
\hline & 96.73156 & 3.7 & 2 & $-46 \%$ & 3.8 & $2.70 \%$ \\
\hline & 97.78194 & 5.5 & 2.4 & $-56 \%$ & 5.7 & $3.64 \%$ \\
\hline & 98.72078 & 6.8 & 2.6 & $-62 \%$ & 7 & $2.94 \%$ \\
\hline & 99.74364 & 7.4 & 2.8 & $-62 \%$ & 7.7 & $4.05 \%$ \\
\hline & 99.99955 & 8.1 & 3 & $-63 \%$ & 8.4 & $3.70 \%$ \\
\hline
\end{tabular}

Table 2. Heat dissipation when $100 \mathrm{Wp}$ PV modules use supercapacitor loading.

\begin{tabular}{lllll}
\hline $\begin{array}{l}\text { Module wattage } \\
(\mathrm{Wp})\end{array}$ & $\begin{array}{l}\text { SC-value } \\
(\mathrm{F})\end{array}$ & $\begin{array}{l}\text { Insolation } \\
\left(\mathrm{W} / \mathrm{m}^{2}\right)\end{array}$ & $\begin{array}{l}\text { Charging- } \\
\text { current }(\mathrm{I})(\mathrm{A})\end{array}$ & $\begin{array}{l}\text { Heat dissipation } \\
(\mathrm{W})=\left(\mathrm{ESR}^{*} \mathrm{I}^{*} \mathrm{I}\right)\end{array}$ \\
\hline 100 & 0.166 & 245 & 1.59 & 0.3337092 \\
100 & 0.166 & 300 & 1.8 & 0.42768 \\
100 & 0.166 & 350 & 2.14 & 0.6045072 \\
100 & 0.166 & 450 & 2.44 & 0.7858752 \\
100 & 0.166 & 580 & 3.31 & 1.4462052 \\
100 & 0.166 & 850 & 4.5 & 2.673 \\
\hline
\end{tabular}

Table 3. Heat dissipation for $100 \mathrm{Wp}$ PV Modules using capacitor loading.

\begin{tabular}{lllll}
\hline $\begin{array}{l}\text { Module-wattage } \\
(\mathrm{Wp})\end{array}$ & $\begin{array}{l}\text { C-value } \\
(\mathrm{F})\end{array}$ & $\begin{array}{l}\text { Insolation } \\
\left(\mathrm{W} / \mathrm{m}^{2}\right)\end{array}$ & $\begin{array}{l}\text { Charging- } \\
\text { current }(\mathrm{A})\end{array}$ & $\begin{array}{l}\text { Heat dissipation } \\
(\mathrm{W})=\left(\mathrm{ESR}^{*} \mathrm{I}^{*} \mathrm{I}\right)\end{array}$ \\
\hline 100 & 0.001 & 200 & 1.535 & 2.2384 \\
100 & 0.001 & 500 & 4.31 & 17.6473 \\
100 & 0.001 & 650 & 4.8 & 21.8880 \\
100 & 0.001 & 750 & 5.616 & 29.9625 \\
\hline
\end{tabular}

and this value transferred to the cell temperature by using the known standard relation [13]. The solar PV modules are Polycrystalline type in the range of $10 \mathrm{Wp}$ to $320 \mathrm{Wp}$. The actual measurement setup is shown in Figure 3. The data acquisition system (DAS) is being made operational on an embedded platform (dsPIC30F4013) making the instrument light-weight and portable. The graphical-LCD (GLCD) display is attached with the measurement setup. 


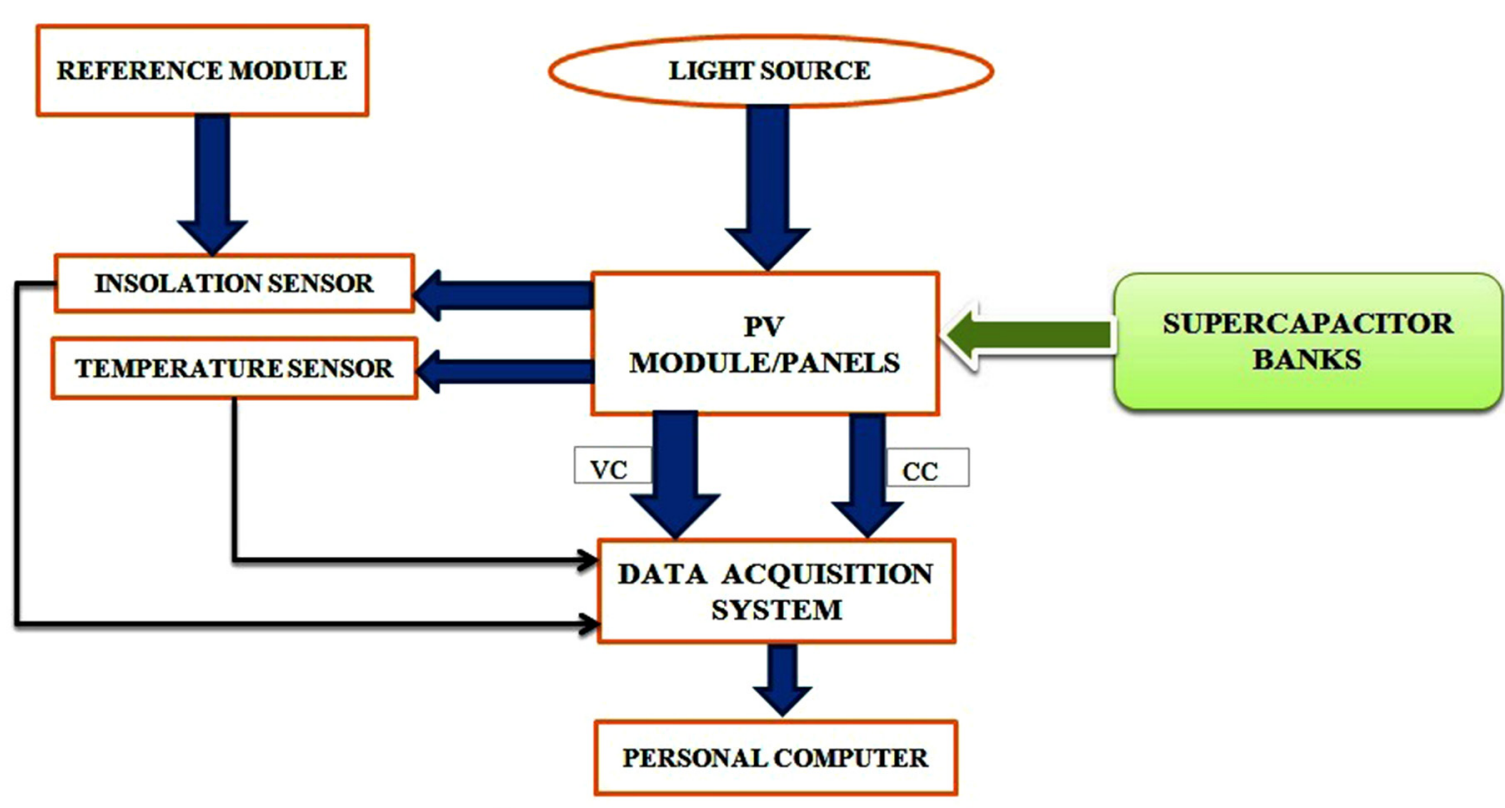

Fig. 2. Functional blocks of the testing setup.

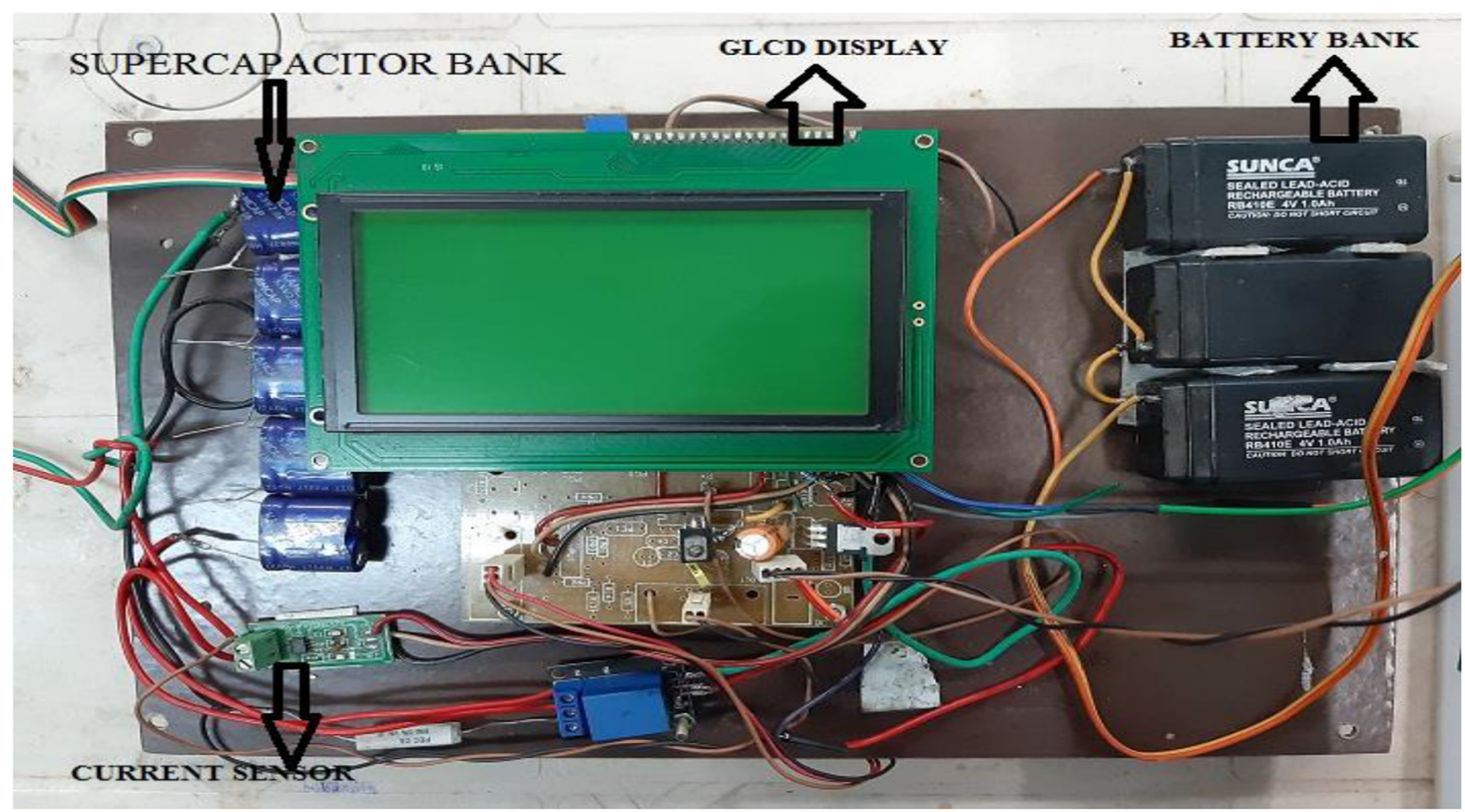

Fig. 3. Components of author $V-I$ measurement setup.

\subsection{Configuration of the SC bank}

The task of choosing the elements of the SC bank was performed with initial priority on low ESR [14] values. The SC banks were configured in two steps:

- In the 1st phase, the PV Module's capacity is considered between $10 \mathrm{Wp}$ to $100 \mathrm{Wp}$. Since the $V_{\text {oc }}$ of the 10 watts to $100 \mathrm{Wp}$ PV modules lie between $21 \mathrm{~V}$ and $25 \mathrm{~V}$ levels, six numbers of series connected $1 \mathrm{~F}, 5.5 \mathrm{~V}$ supercapacitors with ESR values (0.022 ohms) were chosen. For the first case, the simple Kamcap supercapacitors have been used, where the equivalent capacitance of the $\mathrm{SC}$ Bank $=1$ / $6=0.166 \mathrm{~F}$ (seen from Fig. 3).

- In the second stage, the largest capacity building block in Indian PV arrays is considered. Since the $V_{\mathrm{OC}}$ of a $300 \mathrm{Wp}$ PV module is $48 \mathrm{~V}$, lowest ESR values $(0.022 \Omega)$, 


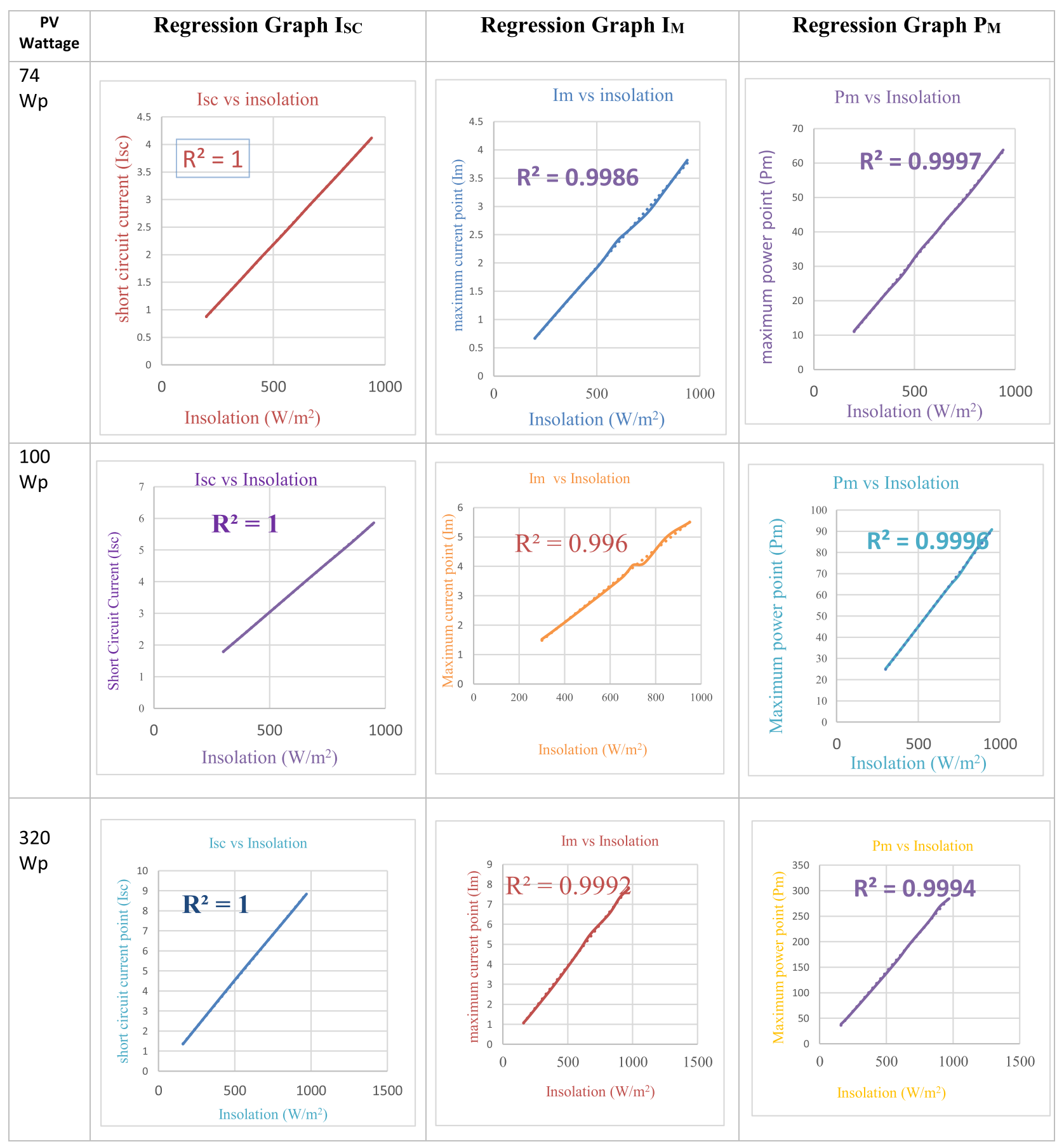

Fig. 4. Linearity check for the solar PV parameters against insolation variation.

supercapacitor bank has been constituted with nine numbers of $7.5 \mathrm{~F}, 5.5 \mathrm{~V}$ supercapacitors. A series configuration constitutes an equivalent capacitance value $0.83 \mathrm{~F}(7.5 / 9)$.

\section{Quality of measurement}

It may be mentioned at the outset that Poly-Si PV modules technology currently enjoys the largest share of Indian PV market. Accordingly, authors group has planned the entire schedule of measurement with a leading PV industry in
Kolkata. Analysing the aforesaid set of results, a no. of essential figures of merit transpires with a reasonable degree of consistency. Following figures of merit has been envisaged.

\subsection{Regression analysis (RA)}

Regression analysis [15] was done for $I_{\mathrm{sc}}, I_{m}$ and $P_{m}$ of PV modules with changing insolation levels. Figure 4 shows values of regression co-efficient $\left(R^{2}\right)$ consistently above 0.95 was obtained for $74 \mathrm{~W}, 100 \mathrm{~W}, 320 \mathrm{~W}$ poly-Si modules. 


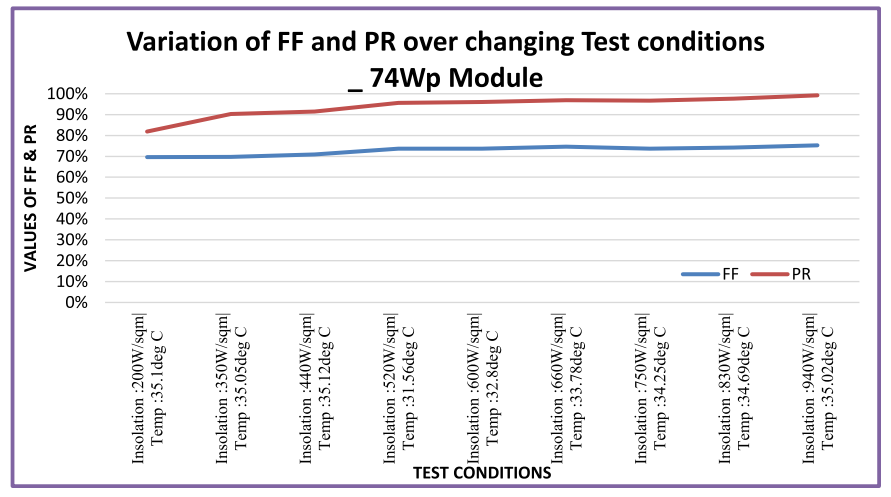

Fig. 5. FF and $\mathrm{PR}$ variation with varying insolation for $74 \mathrm{Wp}$ PV modules.

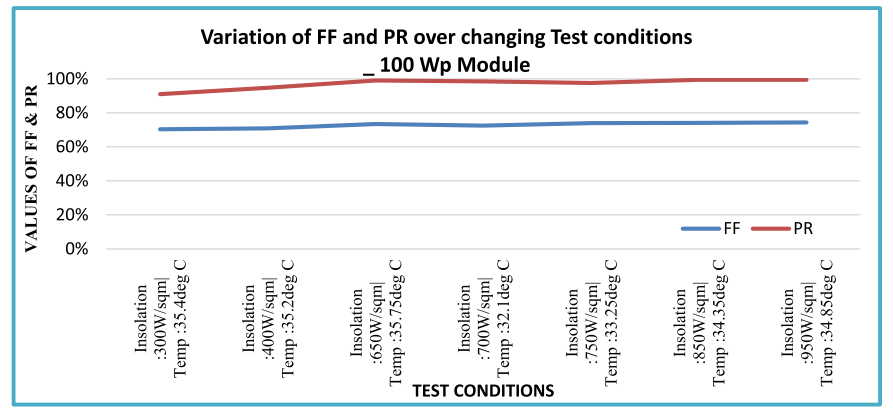

Fig. 6. $\mathrm{FF}$ and $\mathrm{PR}$ variation with varying insolation for $100 \mathrm{Wp}$ PV modules.

\subsection{Fill factor (FF)}

It is the ratio of area covered by $I_{m}-V_{m}$ rectangle with area covered by $I_{\mathrm{sc}}-V_{\mathrm{oc}}$ which is given in equation (1) using standard symbols.

$$
\mathrm{FF}=\left(V_{m} \times I_{m}\right) /\left(I_{\mathrm{sc}} \times V_{\mathrm{oc}}\right)
$$

Fill factor is an intrinsic property of any PV generator and usually from 0.6 to 0.85 for good quality PV generators. The FF variations with varying insolations and temperature are shown in Figures 5-7. However, in real test conditions FF values lies in the range of 0.7 to 0.8 .

\subsection{Performance ratio (PR)}

The PR is stated as the ratio of the actual and theoretical energy outputs of the PV plant/PV module [16]. Mathematically performance ratio is represented as

$$
\mathrm{PR}=\left(\mathrm{mP}_{\mathrm{MPP}} / \mathrm{P}_{\mathrm{STC}}\right) \times\left(1000 \mathrm{~W} / \mathrm{m}^{2} / \mathrm{G}_{\mathrm{POA}}\right)
$$

where, $\mathrm{mP}_{\mathrm{MPP}}$, measured power in NON-STC condition; $\mathrm{P}_{\mathrm{STC}}$, measured power in STC conditions; $\mathrm{G}_{\mathrm{POA}}$, insolation actually incident on the plane of array.

However, in real field conditions PR values for a PV plant lies between 0.80 and 0.95 . Such values for different wattages of PV modules are shown in Figures 5-7 against varying levels of insolations.

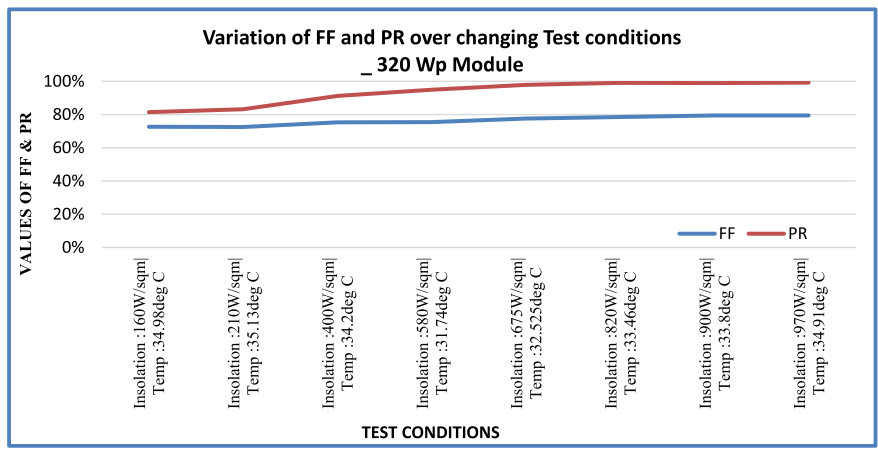

Fig. 7. FF and PR variation with varying insolation for $320 \mathrm{Wp}$ PV modules.

\subsection{Smooth and noise free characteristics}

It can be observed from the set of $I-V$ characteristics presented in Figure 8 that the curves are all having a smooth trace, where the detection of the maximum power point occurs in a unique fashion for all the curves. Further, no kink/noise level is seen around the maximum power point zone. Uncertainty in determination of maximum power point is thereby eliminated.

\subsection{High reproducibility of the measurements}

In line with the classical way of understanding the reproducibility of measurements, in case of PV metrology, the same has to be assessed through the infirmity of quality of the PV performance parameter obtained under naturally varying environmental conditions. Figures $5-7$ projects the two essential PV quality parameter FF and PR against naturally varying levels of climatic condition over a full day. Such an exercise for a particular PV module capacity has been repeated for a set of chosen PV building blocks - $74 \mathrm{Wp}$, $100 \mathrm{Wp}$, and $320 \mathrm{Wp}$ modules. Error-free measurements obtained under various combinations of insolations and temperatures have been projected in Figure $8(4 \times 3$ matrix $)$, where four selected capacity of PV module has been characterized in three different seasons of the year. Thus result gives adequate confidence in the "Reproducibility of the measurements" can be instilled.

\section{Relative power loss (RPL) analysis}

Non-identical current-voltage characteristics of PV modules give rise to power loss when modules are connected in series or in the parallel configuration. Such losses are called Mismatch loss. Mismatch losses normally arise due to relative power loss (RPL) or in the form of shading loss. The shading loss is neglected easily by choosing the appropriate PV installation site. RPL loss is the total output power of Series connection or Parallel connection of PV modules will be less than the sum of the total power output of PV modules as if they are acting individually. Table 4 shows the RPL measurement for $50 \mathrm{Wp}$ and $100 \mathrm{Wp}$ Poly-Si PV modules in Eastern Indian Climatic Zones. In fact, the quality of measurement so proposed by the authors' metrological approach has been 


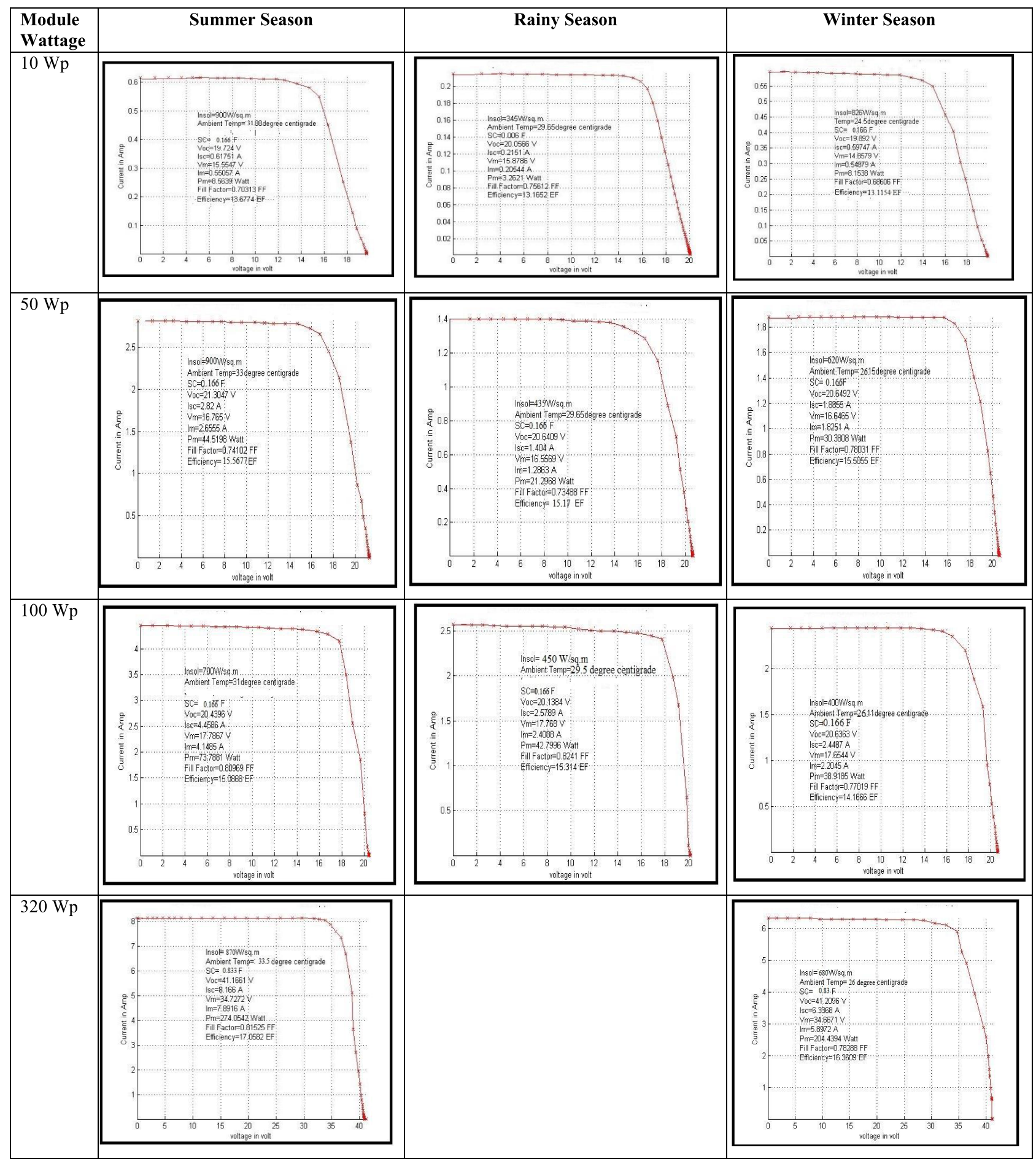

Fig. 8. $V-I$ characteristics of different wattages poly-Si PV modules across three different seasons.

reaffirmed by checking the outdoor performance of small poly-Si PV panels constituted in series and parallel configurations.

\section{Conclusion}

It is to be noted that the PV Modules experimented upon are all Poly-Si PV modules as such modules are the predominant ones in the current Indian market. The basic building blocks (PV modules) chosen for the purpose of experimentation with the new metrological procedure are $74 \mathrm{Wp}, 100 \mathrm{Wp}$, and $320 \mathrm{Wp}$ poly-Si PV modules.

(a) It is seen from Figure 4 that, consistently high values of $R^{2}$ (above 0.98) are found with respect to regression analysis of $I_{\mathrm{sc}}, I_{m}, P_{m}$ of the chosen modules. 
Table 4. RPL measurement for $50 \mathrm{Wp}$ and $100 \mathrm{Wp}$ poly-Si modules.

\begin{tabular}{llll|llll}
\hline \multicolumn{3}{c|}{$50 \mathrm{Wp}$ poly-Si module } & \multicolumn{3}{c}{$100 \mathrm{Wp}$ poly-Si RPL } \\
\hline $\begin{array}{l}\text { Insolation } \\
\left(\mathrm{W} / \mathrm{m}^{2}\right)\end{array}$ & $\begin{array}{l}\text { Temperature } \\
\left({ }^{\circ} \mathrm{C}\right)\end{array}$ & $\begin{array}{l}\text { RPL-series } \\
(\%)\end{array}$ & $\begin{array}{l}\text { RPL-parallal } \\
(\%)\end{array}$ & $\begin{array}{l}\text { Insolation } \\
\left(\mathrm{W} / \mathrm{m}^{2}\right)\end{array}$ & $\begin{array}{l}\text { Temperature } \\
\left({ }^{\circ} \mathrm{C}\right)\end{array}$ & $\begin{array}{l}\text { RPL-series } \\
(\%)\end{array}$ & $\begin{array}{l}\text { RPL-parallal } \\
(\%)\end{array}$ \\
\hline 145 & 31.76 & $2.31 \%$ & $1.91 \%$ & 245 & 27.67 & $1.55 \%$ & $1.40 \%$ \\
245 & 26.51 & $1.76 \%$ & $3.58 \%$ & 300 & 27.61 & $1.56 \%$ & $1.17 \%$ \\
355 & 31.45 & $1.96 \%$ & $1.17 \%$ & 350 & 27.47 & $1.17 \%$ & $0.62 \%$ \\
430 & 26.1 & $1.56 \%$ & $0.96 \%$ & 400 & 27 & $1.57 \%$ & $0.59 \%$ \\
600 & 26.59 & $1.59 \%$ & $0.39 \%$ & 450 & 26.68 & $1.58 \%$ & $0.57 \%$ \\
680 & 28.97 & $1.31 \%$ & $0.94 \%$ & 540 & 25.44 & $0.94 \%$ & $0.42 \%$ \\
770 & 26.56 & $2.12 \%$ & $1.19 \%$ & 600 & 24 & $1.42 \%$ & $0.45 \%$ \\
880 & 25.8 & $1.82 \%$ & $1.15 \%$ & 680 & 22.51 & $1.09 \%$ & $0.54 \%$ \\
\hline
\end{tabular}

(b) From Figures 5-7 are clearly seen that

i) Estimated $\mathrm{FF}$ values for the aforesaid modules are in the range of $70 \%$ to $79 \%$.

ii) The PR values of the building blocks range typically from 90 to $99 \%$ for varying levels of insolations.

(c) Reproducibility of author's metrology through the new SC-based technique has been confirmed on a particular day (Figs. 5-7) and across three different seasons (Fig. 8).

(d) Finally, RPL values for $50 \mathrm{pW}$ and $100 \mathrm{pW}$ PV panels are typically less than $2.5 \%$ and $1.5 \%$ for series and the parallel respectively string of PV modules corresponding to insolation above $300 \mathrm{~W} / \mathrm{m}^{2}$.

Experimental evidence (a) to (d) is a strong indicator of the inherent quality of the new metrology based on supercapacitors. Field trials with Vikram Solar PV modules are in progress for finalizing an appropriate commercial version of the prototype $I-V$ plotter.

\section{References}

1. A. Hsu, Carlin Rosengartin, A. Wein Furter, Y. Xie, Renewable Energy and Energy Efficiency in Developing countries: Contribution to Reducing Global emission, United Nations Environment Programme, Third Report, 2017

2. The Jawaharlal Nehru National Solar Mission (National Solar Mission), Launched by MNNRES, Govt of India, 2011

3. S. Basu Pal, T. Belel, K. Das (Bhattacharya), D. Mukherjee, A Simple cost Effective method of Characterizing PV Cell/ Modules using Supercapacitor, in WCPEC6-November2014, Kyoto, Japan, 2014

4. S. Basu Pal, K. Das (Bhattacharya), D. Mukherjee, D. Paul, Electrical characterization of PV modules employing supercapactors - a scalable method for field metrology, in International Conference on Renewable Energies and Power Quality(ICREPQ), Spain, 2017
5. S. Basu Pal, K. Das (Bhattacharya), D. Mukherjee, D. Paul, Estimating of curve tracing time in supercapacitor based PV characterization, J. Inst. Eng. (India) Ser. B 385-391 (2017)

6. Y. Kuai, S. Yuvarajan, An electronic load for testing photovoltaic panels, J. Power Sources 154, 308-313 (2005)

7. A. Sahbela, N. Hassan, M.M. Abdelhameed, A. Zekry, Experimental performance characterization of photovoltaic modules using DAQ, Energy Proc. 36, 323-332 (2013)

8. M.M. Mahmoud, Transient analysis of a PV power generator charging a capacitor for measurement of the $I-V$ characteristics, Renew. Energy 31, 2198-2206 (2006)

9. F. Spertino, J. Ahmad, A. Ciocia, P. Di Leo, A.F. Murtaza, M. Chiaberge, Capacitor charging method for $I-V$ curve tracer and MPPT in photovoltaic systems, Solar Energy 119, 461-473 (2015)

10. Y. Erkaya, P. Moses, S. Marsillac, On-site characterization of PV modules using a portable, MOSFET based capacitive load, in 43rd IEEE Photovoltaic Specialist conference (2016) pp. 3119-3122

11. Zhikong et al., A capacitor based fast $I-V$ characteristics $I-V$ tester for photovoltaic arrays, Energy Proc. 145, 381-387 (2018)

12. Maxwell Technologies Supercapacitor Technical Note, link: http://www.afs.enea.it/project/oldprojects/protosphera/ Proto-Sphera Full Documents/Messa in Opera MultiPinch/Alimentazioni_con_SuperCapacitors/Alimentatore Pinch/Maxwell/07\%20UC\%20vs\%20Batteries.pdf.

13. D.L. King, W.E. Boyson, J.A. Kratochvill, Photovoltaic Array Performance Model, Sandia Report, No: SAND20043535,2004

14. AVX Supercapacitor, Available Online http://www.farnell. com/datasheets/2310575.pdf

15. D.C. Montgomery, E.A. Peck, G. Geoffrey Vining, in Introduction to Linear Regression Analysis, 5th edn. (Willey Publishers, 2012)

16. A. Louwen et al., Comprehensive characterization and analysis of PV module performance under real operating conditions, Prog. Photovolt. Res. Appl. 25, 218-232 (2017)

Cite this article as: Sudipta Basu Pal, Rahul Kumar, Konika Das Bhattacharya, Dipankar Mukherjee, Debkalyan Paul, Supercapacitor based PV measurement technique - quality assessment with poly-Si PV modules at IIEST, Kolkata, Int. J. Metrol. Qual. Eng. 10, 9 (2019) 